\title{
Thermal Spectroscopy and Kinetic Studies of PEO/PVDF Loaded by Carbon Nanotubes
}

\author{
Laila Hussein Gaabour \\ Department of Physics, Girl's Faculty of Science, King Abdul-Aziz University, Jeddah, Saudi Arabia \\ Correspondence should be addressed to Laila Hussein Gaabour; d_lhj@hotmail.com
}

Received 20 March 2015; Revised 16 May 2015; Accepted 17 May 2015

Academic Editor: Christian M. Julien

Copyright ( 2015 Laila Hussein Gaabour. This is an open access article distributed under the Creative Commons Attribution License, which permits unrestricted use, distribution, and reproduction in any medium, provided the original work is properly cited.

\begin{abstract}
Nanocomposites of polyethylene oxide (PEO) and polyvinylidene fluoride (PVDF) without and with low content of single and multiwalled carbon nanotubes (SWCNTs-MWCNTs) were prepared and studied by thermogravimetric analysis (TGA) using different heating rate. TGA results indicate that the thermal stability of neat PEO/PVDF blend was improved with both heating rate and incorporation of carbon nanotubes (CNTs). The degradation temperature for neat blend was lower than those of the nanocomposites after adding both SWCNTs and MWCNTs. As increase of heating rate, the onset of decomposition is irregularly moved to higher temperatures. This indicates that the thermal stability of the polymeric matrices has been improved after addition of CNTs. The residual weight of the samples left increased steadily with adding of both SWCNTs and MWCNTs. Kinetic thermodynamic parameters such as activation energy, enthalpy, entropy, and Gibbs free energy are evaluated from TGA data using Coats-Redfern model. The values of all parameters irregularly decrease with increasing of heating rate due to increasing of heating rate temperature, the random scission of macromolecule chain in the polymeric matrices predominates and the activation energy has a lower value.
\end{abstract}

\section{Introduction}

Since the discovery of carbon nanotubes (CNTs) in 1991 by Iijima [1], they have been looked at by a wide range of researchers $[2,3]$. Polymer and/or polymer blend incorporated with CNTs have intensive interest because of their unique and valuable thermal and other properties compared with pure polymers [4-6]. One of advantages of CNTs is a reinforcement filler to induce a better adhesion with polymeric matrix, which is an important factor to enhancement of the nanocomposite properties [7]. The properties of these nanocomposites depend on several factors with the addition of CNTs to the polymer like synthetic and purification process, amount and type of CNTs impurities, diameter, length, and ratio of nanotube in the composites $[8,9]$. The addition of a small amount $(\leq 0.5 \mathrm{wt} \%)$ of CNTs strongly improves the properties of pure polymer [10-12].

The CNTs have attracted much attention to apply for hydrogen storage, chemical sensors, and nanoelectronic devices. They are used as extremely strong nanoreinforcements for composites, which possess extraordinarily high strength with low weight and moderate electrostatic discharge properties [13]. Single walled carbon nanotubes (SWCNTs) consist of a single graphene sheet wrapped into cylindrical tubes with diameters around $2 \mathrm{~nm}$ with some micrometers length. Multiwalled carbon nanotubes (MWCNTs) consist of sets of SWCNTs having larger diameters [1416].

Thermogravimetric analysis (TGA) is a process in which substance is decomposed in the presence of increase of temperature which causes breakage in the bonds within the molecules. The sample weight decreases slowly as the reaction begins, then decreases rapidly over a comparatively narrow temperature range, and finally levels off as the reactants become spent. The shape of TGA curve depends primarily upon the kinetics parameters. The estimated values of the kinetic parameters are very important in study of the thermal stability of the substances [17]. In the thermal techniques, 
the study of individual polymer and how its thermal properties are is affected by dispersion of CNTs in polymeric matrices [18].

CNTs as filler incorporated polymer or polymer blend nanocomposites are excellent candidates for traditional thermal material owing to their good thermal stability, flexible processability, low weight, and excellent physical performance, which are in focus in the electronic and industry applications. CNT incorporation has previously been reported to improve the thermal and electrical properties of a range of polymers. Some researchers proposed thermal and electrical property improvements as a function of CNT type, degree of dispersion, and loading ratio $[19,20]$.

This work reports the synthesis and investigation of PEO/PVDF nanocomposite films doped with low content of single and multiwalled carbon nanotubes using a simple method and studies the effect of different heating rate and kinetic parameters to achieve a dramatic enhancement in thermal properties.

\section{Experimental and Theoretical Details}

2.1. Experimental. Polyethylene oxide (PEO) has the following specifications: molecular weight $\approx 900,000$, linear formula is $\left(-\mathrm{CH}_{2} \mathrm{CH}_{2} \mathrm{O}-\right)_{n}$, melting temperature $=65^{\circ} \mathrm{C}$, and density is $1.21 \mathrm{~g} / \mathrm{mL}$. Polyvinylidene fluoride (PVDF) has the following specifications: molecular weight $\approx 180,000$, linear formula is $\left(-\mathrm{CH}_{2} \mathrm{CF}_{2}-\right)_{n}$, melting temperature $=165^{\circ} \mathrm{C}$, and density is $1.78 \mathrm{~g} / \mathrm{mL}$ at $25^{\circ} \mathrm{C}$. The two polymers were obtained from Sigma-Aldrich Company, USA. Both of single and multiwalled carbon nanotubes (SWCNTs-MWCNTs) with $\mathrm{COOH}$ functional groups (NTX10) were obtained from Nanothinx, Greece. CNTs-COOH has diameter 0.8-1.4, length $\geq$ $5 \mu \mathrm{m}$, and purity $85 \%$.

Polyethylene oxide (PEO) and polyvinylidene fluoride (PVDF) were dried in a vacuum oven at $50^{\circ} \mathrm{C}$ before being used to remove moisture content. $2 \mathrm{gm}$ of $\mathrm{PEO}$ and $8 \mathrm{gm}$ of PVDF were dissolved in dimethyl sulfoxide (DMSO) as a solvent with stirring at $60^{\circ} \mathrm{C}$ about $6 \mathrm{~h}$ to obtain a good solution of the polymer blend. The polymer solution was cooled at room temperature about $3 \mathrm{~h}$ to remove any air bubbles during stirring. $0.1 \mathrm{gm}$ of both SWCNTs and MWCNTs was added separately to $10 \mathrm{~mL}$ of DMSO on a beaker. Then, the beaker was immersed in ultrasonic(Eltrosonic Type 07) to give a good suspension about $40 \mathrm{~min}$ with $2 \mathrm{~min}$ as time interval. The PEO/PVDF nanocomposites containing CNTs were prepared using casting method by the following procedure: suspension solutions of SWCNTs and MWCNTs were added dropwise to blend solution with continuous stirring and under ultrasonic. After careful mixing blend solution containing CNTs was prepared by casting method. $\mathrm{PEO} / \mathrm{PVDF} / \mathrm{CNT}$ films were obtained by peeling off from glass Petri dishes and putting them in oven at $60^{\circ} \mathrm{C}$ to evaporate the solvent. The obtained films were, namely, pure PEO, PVDF, PEO/PVF, PEO/PVDF/SWCNTs, and PEO/PVDF/ MWCNTs.

The thermogravimetric analysis (TGA) was used to characterize the decomposition and thermal stability of prepared samples by Perkin-Elmer TGA-7. The mass of the samples amount (5.4-8.8 mg) was recorded while temperature is increased at a heating rate of $5,10,15$, and $25^{\circ} \mathrm{C} \cdot \mathrm{min}^{-1}$ and the samples were heated from room temperature to $800^{\circ} \mathrm{C}$ in nitrogen atmosphere.

2.2. Theoretical Background. Generally in the reactions kinetic, the thermal degradation of a solid polymer can be shown as follows: Solid $(S) \rightarrow$ solid $\left(S^{\prime}\right)+$ gas $(G)$, where $S$ is the starting solid material and $S^{\prime}$ and $G$ are the different products during the disappearance of Solid (S) [21].

The kinetics parameters of such reactions are described by various models taking into account the special features of their mechanisms. Usually the degree of decomposition $(\alpha)$ is used to study the reactions kinetic as [22]

$$
\alpha=\frac{m_{i}-m_{t}}{m_{i}-m_{f}},
$$

where $m_{i}, m_{f}$, and $m_{t}$ are the initial, final, and mass of the sample at the time $t$, respectively.

In general, the kinetic equation has been proposed to characterize and analyze thermogravimetric measurements and curves [23-25]. Using the degree of decomposition, the rate of reaction can be described as the product of two separate functions of temperature and conversion by

$$
\frac{d \alpha}{d t}=k f(\alpha)
$$

where $k$ is the rate constant and $f(\alpha)$ is the conversion function dependent on the mechanism of decomposition. It has been established that the rate constant $k$ is of the Arrhenius equation as

$$
k=A e^{-E / R T}
$$

where $A$ is the preexponential factor, $E$ is the activation energy, $R$ is the gas constant, and $T$ is the absolute temperature. Substituting (3) into (2), we get

$$
\frac{d \alpha}{d t}=A e^{-E / R T} f(\alpha) .
$$

If the temperature of a sample is changed at constant value of the linear heating rate $\varphi(d T / d t)$, the variation of the degree of conversion can be analyzed as a function of temperature, which depends on the time of heating. Then the reaction rate is

$$
\frac{d \alpha}{d t}=\frac{A}{\varphi} e^{(-E / R T)} f(\alpha) .
$$

On integration and approximation of (5), this equation can be rearranged in the following form:

$$
g(\alpha)=\frac{A}{\varphi} \int_{T_{o}}^{T} e^{(-E / R T)} d T,
$$

where $g(\alpha)$ is a function of $\alpha$ dependent on the mechanism of the reaction. The integral on the right-hand side is known as temperature integral and has no closed form solution. By 
the Coats-Redfern approximation method, the logarithm of the function $g(\alpha)$ is

$$
\ln \left(\frac{g(\alpha)}{T^{2}}\right)=\ln \left\{\frac{A R}{\varphi E}\left(1-\frac{2 R T}{E}\right)\right\}-\frac{E}{R T} .
$$

The part $\ln (A R / \varphi E)(1-2 R T / E)$ is reasonably constant for most values of $E$ and in the temperature range over which most reactions occur. However, both $E$ and $A$ vary with the heating rate of temperature.

\section{Results and Discussion}

3.1. Thermogravimetric Analysis (TGA). Figures 1-3 illustrate the thermogravimetric analysis (TGA) and derivative thermogravimetry (DTG) curves results generated on samples of neat PEO, PVDF, and PEO/PVDF blend and the blend with SWCNTs and MWCNTs nanocomposites at heating rates ranging between $5,10,15$, and $25^{\circ} \mathrm{C} \cdot \mathrm{min}^{-1}$ in nitrogen atmosphere from room temperature to $800^{\circ} \mathrm{C}$.

Generally, it is seen that all curves are smooth weightloss curves. The decomposition behaviors at all values are similar. In Figure 1, there are two steps of decomposition in all samples. The first step is attributed to PEO decomposition and the other step is attributed to PVDF decomposition. The lower values of percentage of weight loss in the first decomposition step for PEO which are nearly from 3.2 to $20 \%$ may be due to splitting or volatilization of small molecule and evaporation of moisture. The other decomposition regions in TGA curves which cover a wider temperature range including the decomposition of PVDF have a percentage of weight loss from 33 to $70 \%$. The difference in thermal decomposition behavior of the investigated samples can be seen more clearly from the derivative thermogravimetric (DTG) curves as shown in Figure 2.

The derivative thermogravimetric curves show two temperature broad peaks $\left(T_{p}\right)$ corresponding to the two degradation regions. The values of these degradation temperatures (onset of inflection) from Figure 1 in the first and the second steps for the samples at heating rates are listed in Tables 1 and 2. It is observed that the degradation temperature for neat blend was lower than those of the nanocomposites after adding both SWCNTs and MWCNTs, and as the heating rate is increased, the onset of decomposition is irregularly moved to higher temperatures. This indicates that the thermal stability of the polymeric matrices has been improved after addition of CNTs. It is seen also that the residual weight of the materials left increased steadily with the adding of both SWCNTs and MWCNTs loading.

Moreover, the thermodynamics activation parameters of the main decomposition process in the second degradation region were evaluated by the Coats-Redfern equation [26, 27] which is a typical integral method and can be represented in the following form:

$$
\int_{0}^{\alpha} \frac{d \alpha}{(1-\alpha)^{n}}=\frac{A}{\varphi} \int_{T_{1}}^{T_{2}} e^{(-E / R t)} d t
$$

For convenience of integration the lower limit $T_{o}$ is usually taken as zero. This equation on integration gives

$$
\ln \left[-\frac{\ln (1-\alpha)}{T^{2}}\right]=-\frac{E^{*}}{R T}+\ln \frac{A R}{\varphi E^{*}} .
$$

A plot of $\ln \left[-\ln (1-\alpha) / T^{2}\right]$ against $1 / T$ according to (9) (the figures are not here for sake of brevity) should give a straight line whose slope is directly proportional to the apparent activation energy $\left(-E^{*} / R\right)$.

The value of apparent activation energy $\left(E^{*}\right)$ was calculated from the slope of the plot as $E^{*}=2.303 R \times$ slope. The estimated values of activation energies of the samples are decreased with increasing of heating rate and addition of CNTs indicates that CNTs intensively affect the polymer.

The entropy of activation $\Delta S^{*}$ in $(\mathrm{J} / \mathrm{K} . \mathrm{mol})$, the enthalpy of activation $\Delta H^{*}$, and the Gibbs free function $\Delta G^{*}$ were calculated by using the data from (9) and the following equations [28-30]:

$$
\begin{aligned}
\Delta S^{*} & =R \ln \left(\frac{A h}{K_{B} T_{p}}\right), \\
\Delta H^{*} & =E^{*}-R T_{p}, \\
\Delta G^{*} & =\Delta H^{*}-T_{p} \Delta S^{*},
\end{aligned}
$$

where $K_{B}$ is Boltzmann constant, $h$ is Planck's constants, and $T_{p}$ is the temperature involved in the calculation selected as the DTG peak temperature [31]. The entropy $\Delta S^{*}$ gives information about the degree of order of the system, the enthalpy $\Delta H^{*}$ gives information about the total thermal motion, and Gibbs or free energy $\Delta G^{*}$ gives information about the stability of the system.

According the Coats-Redfern method, the calculated thermodynamic parameters values $\left(E^{*}, \Delta S^{*}, \Delta H^{*}\right.$, and $\Delta G^{*}$ ) are recorded in Table 3. It is clear that the values of all thermodynamic parameters decrease irregularly in the second decomposition step for all nanocomposites with increase in both heating rates and temperature. This can be discussed as due to increasing heating rate temperature, the random scission of macromolecule chain in the polymeric matrices predominates and the activation energy has a lower value. Moreover, all the samples have negative entropy which indicates ordered systems and more ordered activated states that may be possible through the chemisorption of other light decomposition products.

\section{Conclusion}

Solid polymer blend films based on PEO/PVDF unfilled and filled with low concentration of single and multiwalled carbon nanotubes were prepared using casting method. Thermal studies at different heating rates and kinetic parameters were performed using thermogravimetric analysis (TGA) and its first derivative (DTG). The kinetic thermodynamic parameters such as activation energy, enthalpy, entropy, and Gibbs free energy were evaluated from TGA data using CoatsRedfern relation. The lower values of percentage weight loss 

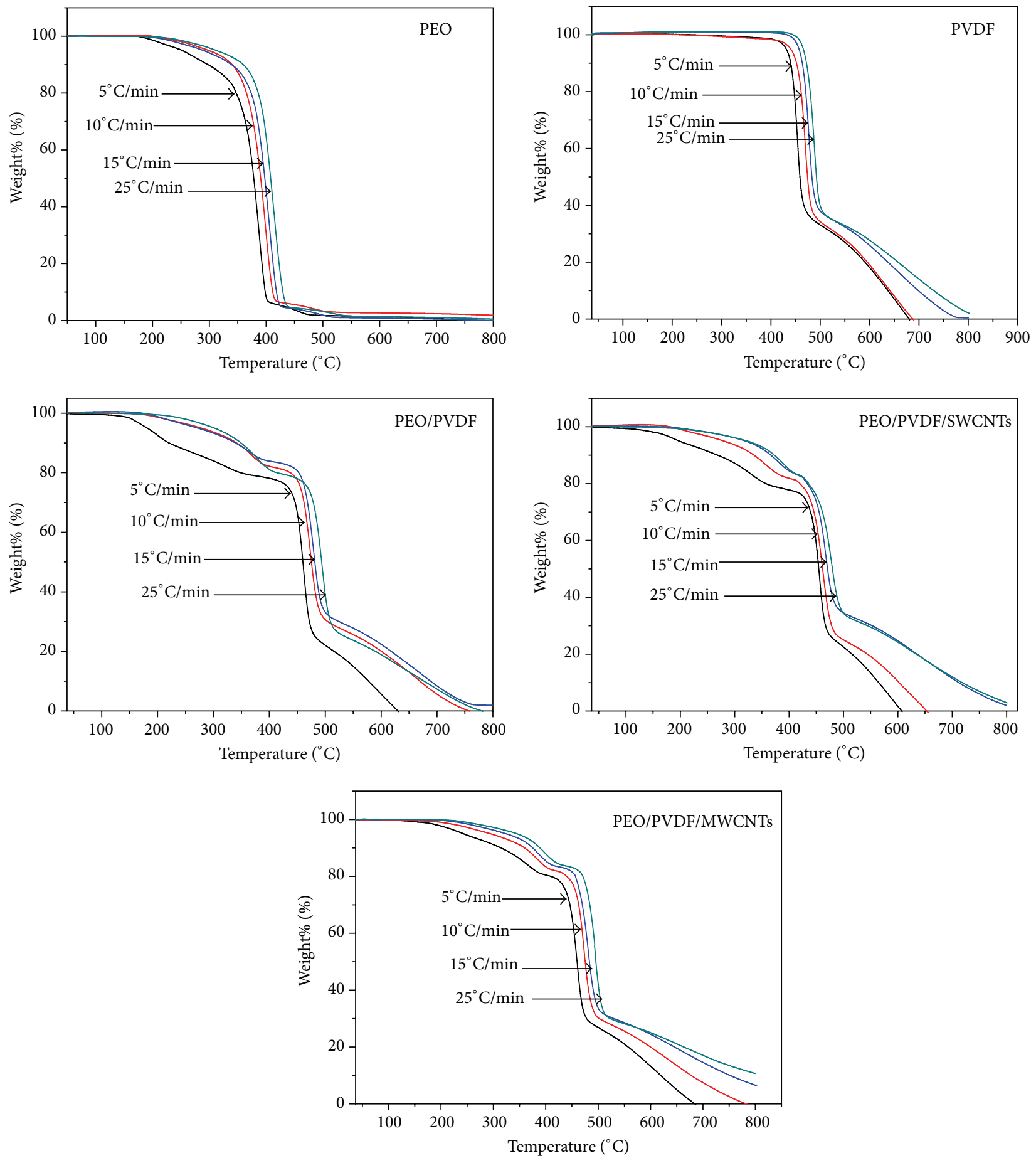

Figure 1: TGA thermograms of neat PEO, PVDF, and PEO/PVDF blend and the blend with SWCNTs and MWCNTs nanocomposites at heating rates ranging between $5,10,15$, and $25^{\circ} \mathrm{C} \cdot \mathrm{min}^{-1}$.

TABLE 1: The values of degradation temperature $\left(T_{d}\right)$ in the first step at 5, 10, 15, and 25 heating rates.

\begin{tabular}{lcccc}
\hline Sample & \multicolumn{3}{c}{ Degradation temperature $\left(T_{p}\right)$ in the first step } \\
& $5^{\circ} \mathrm{C} \cdot \mathrm{m}^{-1}$ & $10^{\circ} \mathrm{C} \cdot \mathrm{m}^{-1}$ & 366.20 & $25^{\circ} \mathrm{C} \cdot \mathrm{m}^{-1}$ \\
\hline PEO/PVDF & 360.14 & 364.10 & 374.56 & 38.23 \\
PEO/PVDF/SWCNTs & 363.97 & 374.51 & 385.04 & 390.46 \\
PEO/PVDF/MWCNTs & 366.72 & 383.42 & 392.32 \\
\hline
\end{tabular}



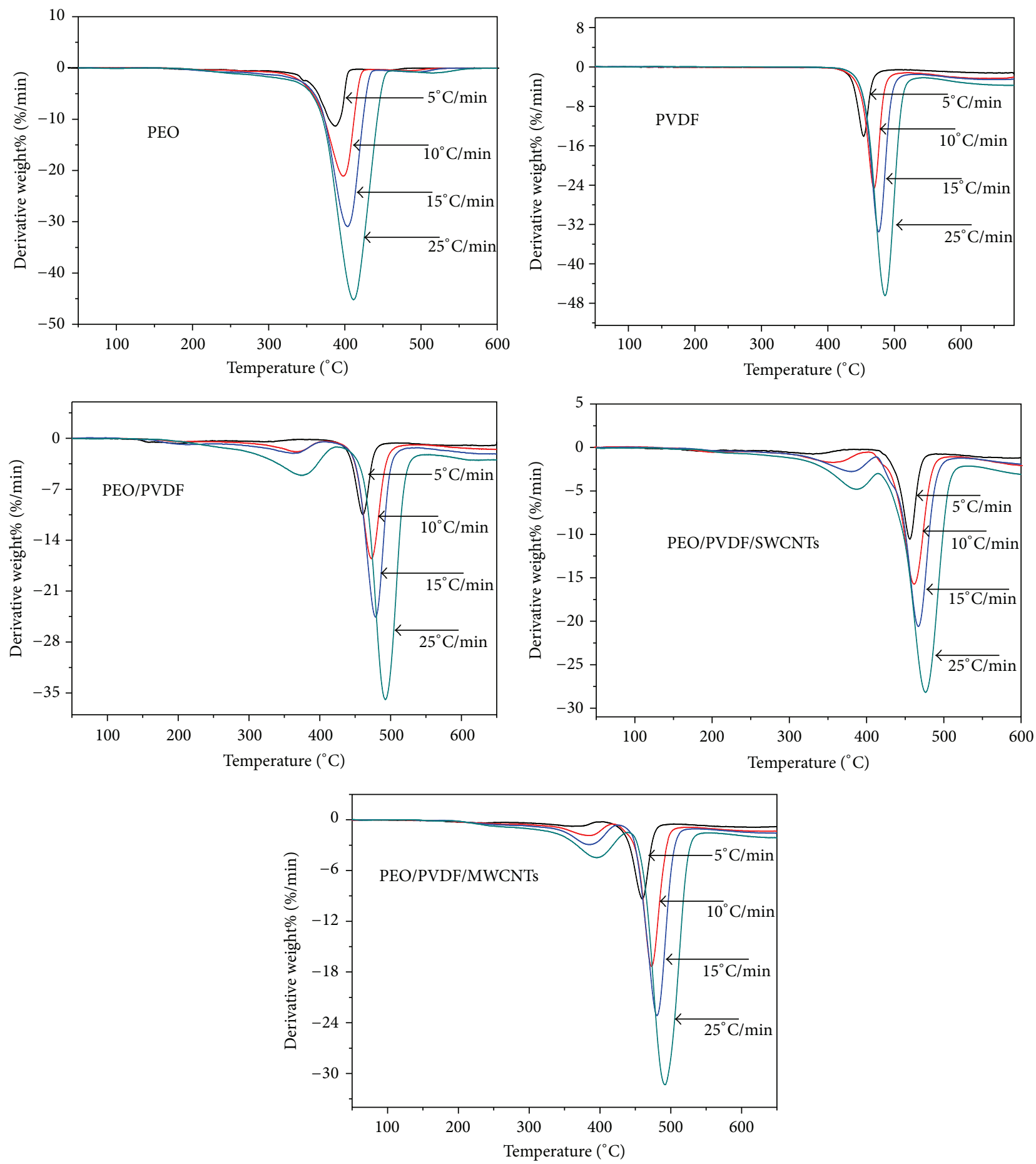

FIGURE 2: TGA thermograms of neat PEO, PVDF, and PEO/PVDF blend and the blend with SWCNTs and MWCNTs nanocomposites at heating rates ranging between $5,10,15$, and $25^{\circ} \mathrm{C} \cdot \mathrm{min}^{-1}$.

TABLe 2: The values of degradation temperature $\left(T_{d}\right)$ in the second step at 5, 10, 15, and 25 heating rates.

\begin{tabular}{lcccc}
\hline Sample & \multicolumn{3}{c}{ Degradation temperature $\left(T_{p}\right)$ in second step } \\
& $5^{\circ} \mathrm{C} \cdot \mathrm{m}^{-1}$ & $10^{\circ} \mathrm{C} \cdot \mathrm{m}^{-1}$ & $15^{\circ} \mathrm{C} \cdot \mathrm{m}^{-1}$ & 478.89 \\
PEO/PVDF & 462.46 & 472.55 & 466.46 & 492.37 \\
PEO/PVDF/SWCNTs & 457.74 & 461.35 & 480.49 & 477.02 \\
PEO/PVDF/MWCNTs & 459.52 & 473.21 & 474.45 \\
\hline
\end{tabular}



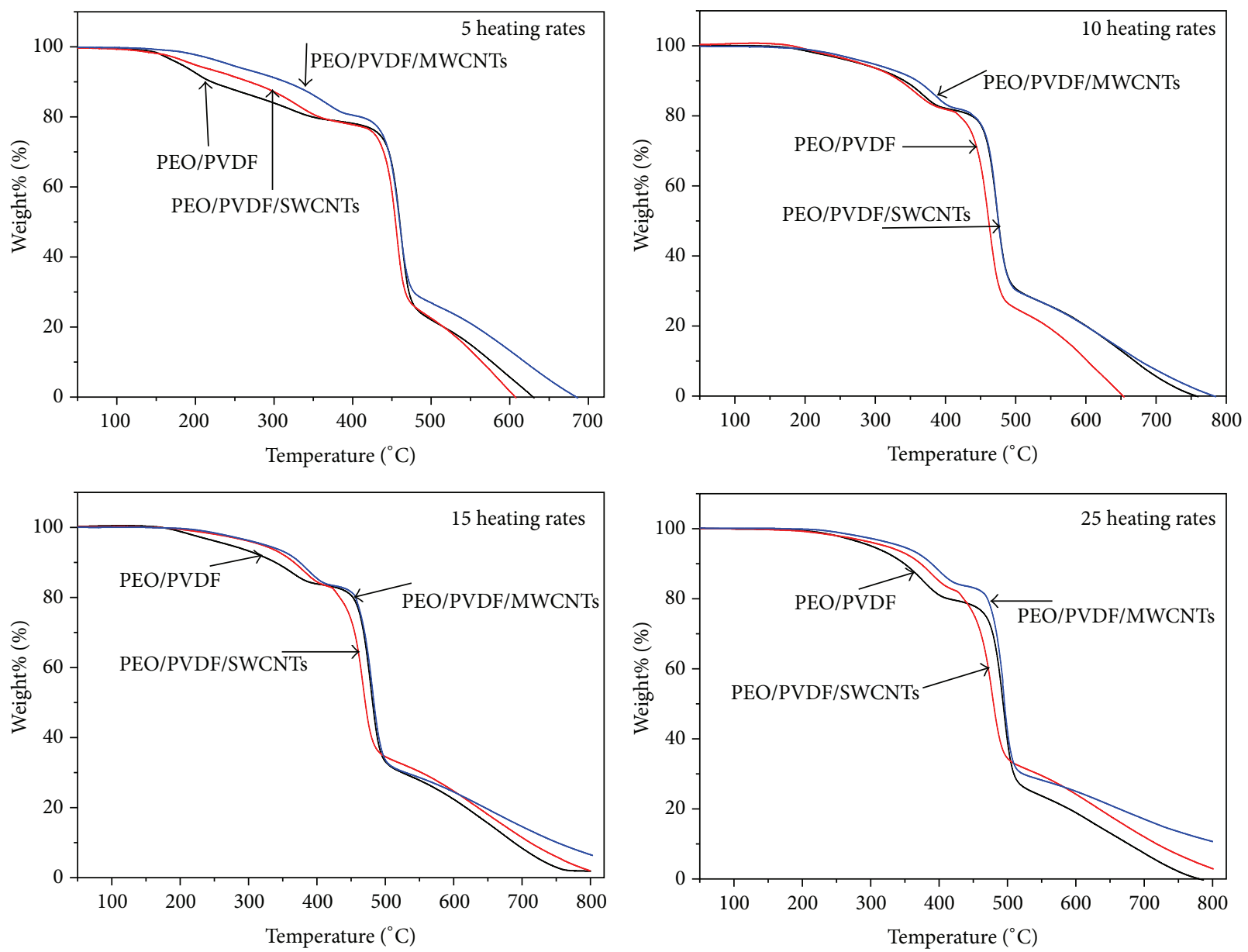

FIgURE 3: TGA thermograms of neat PEO/PVDF blend and the blend with SWCNTs and MWCNTs nanocomposites at heating rates ranging between $5,10,15$, and $25^{\circ} \mathrm{C} \cdot \mathrm{min}^{-1}$.

TABLE 3: Kinetic parameters and activation energy for PEO/PVDF blend and the blend doped with SWCNTs and MWCNTs at 5, 10, 15, and 25 heating rates.

\begin{tabular}{|c|c|c|c|c|c|}
\hline Sample & $\begin{array}{l}\text { Heating rate } \\
\left({ }^{\circ} \mathrm{C} \cdot \mathrm{m}^{-1}\right)\end{array}$ & $\begin{array}{c}\Delta S^{*} \\
(\mathrm{~J} / \mathrm{K} \text { mole }) \\
\end{array}$ & $\begin{array}{c}\Delta H^{*} \\
(\mathrm{KJ} / \text { mole })\end{array}$ & $\begin{array}{c}\Delta G^{*} \\
(\mathrm{KJ} / \text { mole })\end{array}$ & $\begin{array}{c}E^{*} \\
(\mathrm{KJ} / \mathrm{mole})\end{array}$ \\
\hline \multirow{4}{*}{ Blend } & 5 & -205.57 & -5649.34 & 145543.7 & 465.61 \\
\hline & 10 & -200.54 & -5766.49 & 143748.1 & 432.35 \\
\hline & 15 & -197.56 & -5835.84 & 142713.5 & 415.72 \\
\hline & 25 & -193.81 & -5964.54 & 142370.1 & 399.09 \\
\hline \multirow{4}{*}{ Blend/SWCNTs } & 5 & -206.52 & -5585.16 & 143260.8 & 407.41 \\
\hline & 10 & -202.19 & -5756.52 & 142723.5 & 349.20 \\
\hline & 15 & -199.49 & -5823.95 & 141694.7 & 324.26 \\
\hline & 25 & -196.03 & -5936.69 & 141090.6 & 299.32 \\
\hline \multirow{4}{*}{ Blend/MWCNTs } & 5 & -205.11 & -5599.96 & 144646.5 & 490.55 \\
\hline & 10 & -200.87 & -5788.61 & 144107.1 & 415.72 \\
\hline & 15 & -197.58 & -5849.14 & 143029.7 & 415.72 \\
\hline & 25 & -194.12 & -5923.86 & 138886.8 & 374.15 \\
\hline
\end{tabular}


are nearly from 3.2 to $20 \%$ due to splitting or volatilization of small molecule and evaporation of moisture. The main decomposition region in TGA curves has a percentage of weight loss from 33 to $70 \%$. The degradation temperature for neat blend was lower than those of the nanocomposites after adding both CNTs and an increase of heating rate. The decomposition temperature is moved to higher temperatures indicating that the thermal stability of the polymeric has been improved.

\section{Conflict of Interests}

The author declares that there is no conflict of interests regarding the publication of this paper.

\section{References}

[1] S. Iijima, "Helical microtubules of graphitic carbon," Nature, vol. 354, no. 6348, pp. 56-58, 1991.

[2] D. Wang, C. Zhang, Y. Zhang, J. Wang, and D. He, "Synthesis and electrochemical properties of La-doped $\mathrm{Li}_{4} \mathrm{Ti}_{5} \mathrm{O}_{12}$ as anode material for Li-ion battery," Ceramics International, vol. 39, no. 5, pp. 5145-5149, 2013.

[3] T.-F. Yi, Y. Xie, Y.-R. Zhu, R.-S. Zhu, and H. Shen, "Structural and thermodynamic stability of $\mathrm{Li}_{4} \mathrm{Ti}_{5} \mathrm{O}_{12}$ anode material for lithium-ion battery," Journal of Power Sources, vol. 222, pp. 448454, 2013

[4] S. Han, J. Shin, and D. Yoonn, "Synthesis of pure nanosized $\mathrm{Li}_{4} \mathrm{Ti}_{5} \mathrm{O}_{12}$ powder via solid-state reaction using very fine grinding media," Ceramics International, vol. 38, no. 8, pp. 6963-6968, 2012.

[5] F. Liu, M.-M. Tao, and L.-X. Xue, "PVDF membranes with interconnected pores prepared via a Nat-ips process," Desalination, vol. 298, pp. 99-105, 2012.

[6] F. Liu, N. A. Hashim, Y. Liu, M. R. M. Abed, and K. Li, "Progress in the production and modification of PVDF membranes," Journal of Membrane Science, vol. 375, pp. 1-27, 2011.

[7] L. Deng and M. B. Hagg, "Carbon nanotube reinforced PVAm/ PVA blend FSC nanocomposite membrane for $\mathrm{CO}_{2} / \mathrm{CH}_{4}$ separation," International Journal of Greenhouse Gas Control, vol. 26, pp. 127-134, 2014.

[8] I. S. Elashmawi, E. M. Abdelrazek, H. M. Ragab, and N. A. Hakeem, "Structural, optical and dielectric behavior of PVDF films filled with different concentrations of iodine," Physica B: Condensed Matter, vol. 405, no. 1, pp. 94-98, 2010.

[9] L. Yue, M. Zhou, Q. Chen, J. Weng, and Y. Zhang, "Ag/PEO nanocomposite fabricated in a planar magnetron sputtering," Vacuum, vol. 83, no. 9, pp. 1200-1203, 2009.

[10] Z. Y. Cui, B. K. Zhu, L. P. Zhu, X. Z. Wei, C. F. Zhang, and Y. Y. Xu, "Preparation of PVDF/PMMA blend microporous membrane for lithium ion batteries via thermally induced phase separation," Materials Letters, vol. 69, pp. 3809-3811, 2008.

[11] H. P. Zhang, P. Zhang, Z. H. Li, M. Sun, Y. P. Wu, and H. Q. $\mathrm{Wu}$, "A novel sandwiched membrane as polymer electrolyte for lithium ion battery," Electrochemistry Communications, vol. 9, no. 7, pp. 1700-1703, 2007.

[12] L. Yan, Y. S. Li, C. B. Xiang, and S. Xianda, "Effect of nano-sized $\mathrm{Al}_{2} \mathrm{O}_{3}$-particle addition on PVDF ultrafiltration membrane performance," Journal of Membrane Science, vol. 276, no. 1-2, pp. 162-167, 2006.
[13] R. H. Baughman, A. A. Zakhidov, and W. A. De Heer, "Carbon nanotubes-the route toward applications," Science, vol. 297, no. 5582, pp. 787-792, 2002.

[14] M. S. Dresselhaus, G. Dresselhaus, and R. Saito, "Physics of carbon nanotubes," Carbon, vol. 33, no. 7, pp. 883-891, 1995.

[15] T. W. Odo, J. L. Huang, P. Kim, and C. M. Lieber, "Structure and electronic properties of carbon nanotubes," The Journal of Physical Chemistry B, vol. 104, pp. 2794-2809, 2000.

[16] M. A. Terrones, "Science and technology of the twenty-first century: synthesis, properties, and applications of carbon nanotubes," Annual Review of Materials Research, vol. 33, pp. 419501, 2003.

[17] M. B. Othman, H. Md Akil, S. Z. M. Rasib, A. Khan, and Z. Ahmad, "Thermal properties and kinetic investigation of chitosan-PMAA based dual-responsive hydrogels," Industrial Crops and Products, vol. 66, pp. 178-187, 2015.

[18] B. F. Jogi, M. Sawant, M. Kulkarni, and P. K. Brahmankar, "Dispersion and performance properties of carbon nanotubes (CNTs) based polymer composites: a review," Journal of Encapsulation and Adsorption Sciences, vol. 2, pp. 69-78, 2012.

[19] R. Ormsby, T. McNally, C. Mitchell et al., "Effect of MWCNT addition on the thermal and rheological properties of polymethyl methacrylate bone cement," Carbon, vol. 49, no. 9, pp. 2893-2904, 2011.

[20] F.-C. Chiu and Y.-J. Chen, "Evaluation of thermal, mechanical, and electrical properties of PVDF/GNP binary and PVDF/PMMA/GNP ternary nanocomposites," Composites Part A: Applied Science and Manufacturing, vol. 68, pp. 62-71, 2015.

[21] B. Liu, X. Zhao, X. Wang, and F. Wang, "Thermal degradation kinetics of poly(propylene carbonate) obtained from the copolymerization of carbon dioxide and propylene oxide," Journal of Applied Polymer Science, vol. 90, no. 4, pp. 947-953, 2003.

[22] R. Ebrahimi-Kahrizsangi and M. H. Abbasi, "Evaluation of reliability of Coats-Redfern method for kinetic analysis of nonisothermal TGA," Transactions of Nonferrous Metals Society of China (English Edition), vol. 18, no. 1, pp. 217-221, 2008.

[23] Z. Peng and L. X. Kong, "A thermal degradation mechanism of polyvinyl alcohol/silica nanocomposites," Polymer Degradation and Stability, vol. 92, pp. 1061-1071, 2007.

[24] E.-H. M. Diefallah, "Kinetic analysis of thermal decomposition reactions. Part VI. Thermal decomposition of manganese(II) acetate tetrahydrate," Thermochimica Acta, vol. 202, pp. 1-16, 1992.

[25] K. Chetehouna, N. Belayachi, B. Rengel, D. Hoxha, and P. Gillard, "Investigation on the thermal degradation and kinetic parameters of innovative insulation materials using TGA-MS," Applied Thermal Engineering, vol. 81, pp. 177-184, 2015.

[26] A. W. Coats and J. P. Redfern, "Kinetic parameters from thermogravimetric data," Nature, vol. 201, no. 4914, pp. 68-69, 1964.

[27] M. S. Refat, I. Grabchev, J.-M. Chovelon, and G. Ivanova, "Spectral properties of new N,N-bis-alkyl-1,4,6,8-naphthalenediimide complexes," Spectrochimica Acta. Part A. Molecular and Biomolecular Spectroscopy, vol. 64, no. 2, pp. 435-441, 2006.

[28] I. Grabchev, C. Petkov, and V. Bojinov, "Infrared spectral characterization of poly(amidoamine) dendrimers peripherally modified with 1,8-naphthalimides," Dyes and Pigments, vol. 62, no. 3, pp. 229-234, 2004.

[29] J. H. F. Flynn and L. A. Wall, "General treatment of the thermogravimetry of polymers," Journal of Research of the National 
Bureau of Standards A: Physics and Chemistry, vol. 70, no. 6, pp. 487-523, 1996.

[30] L. Vlaev, N. Nedelchev, K. Gyurova, and M. Zagorcheva, "A comparative study of non-isothermal kinetics of decomposition of calcium oxalate monohydrate," Journal of Analytical and Applied Pyrolysis, vol. 81, no. 2, pp. 253-262, 2008.

[31] J. M. Criado, L. A. P. Maqueda, and P. E. S. Jimenez, "Dependence of the preexponential factor on temperature," Journal of Thermal Analysis and Calorimetry, vol. 82, no. 3, pp. 671-675, 2005. 

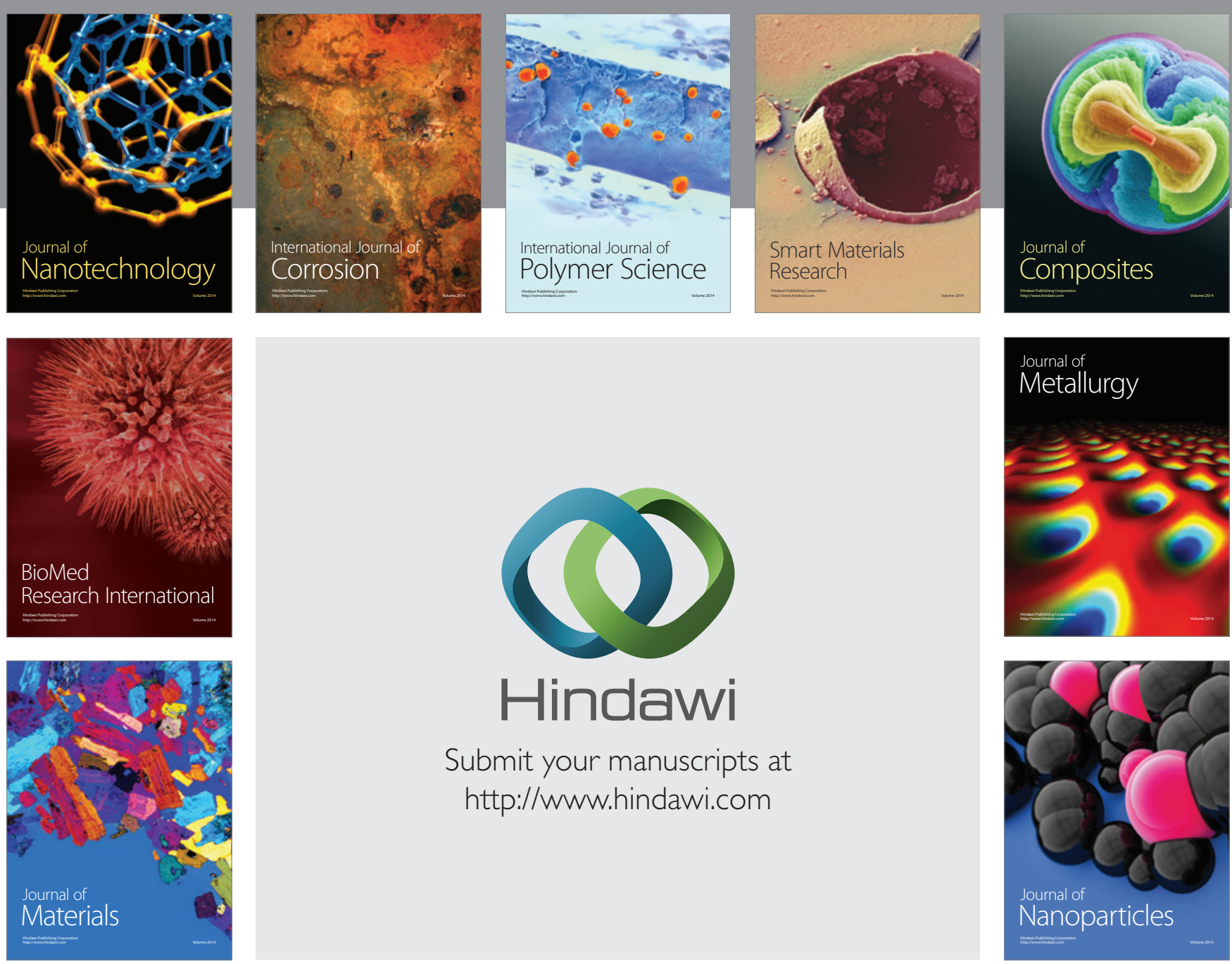

Submit your manuscripts at http://www.hindawi.com
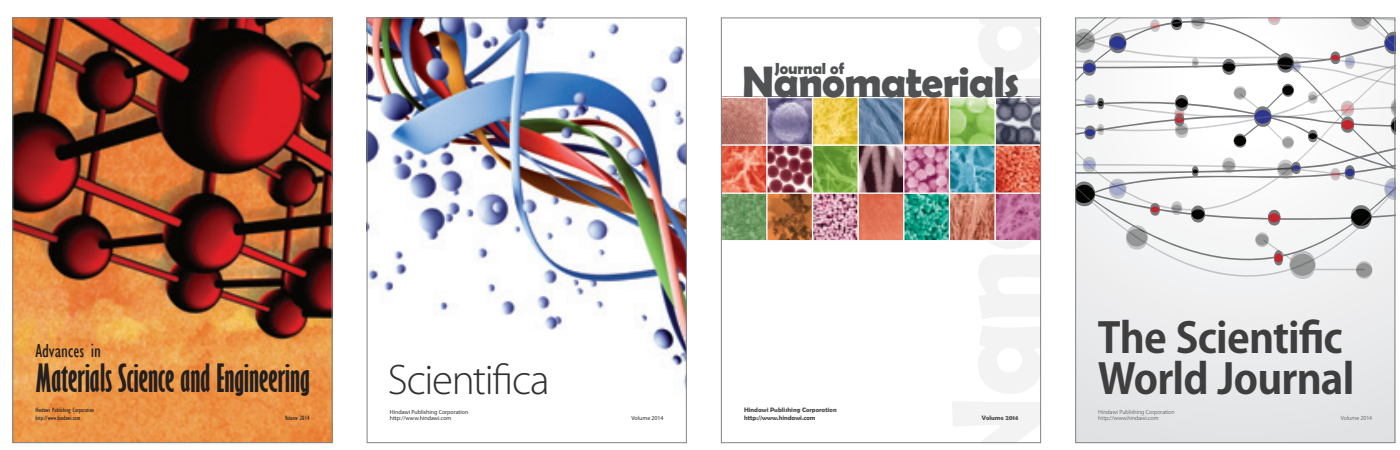

\section{The Scientific World Journal}
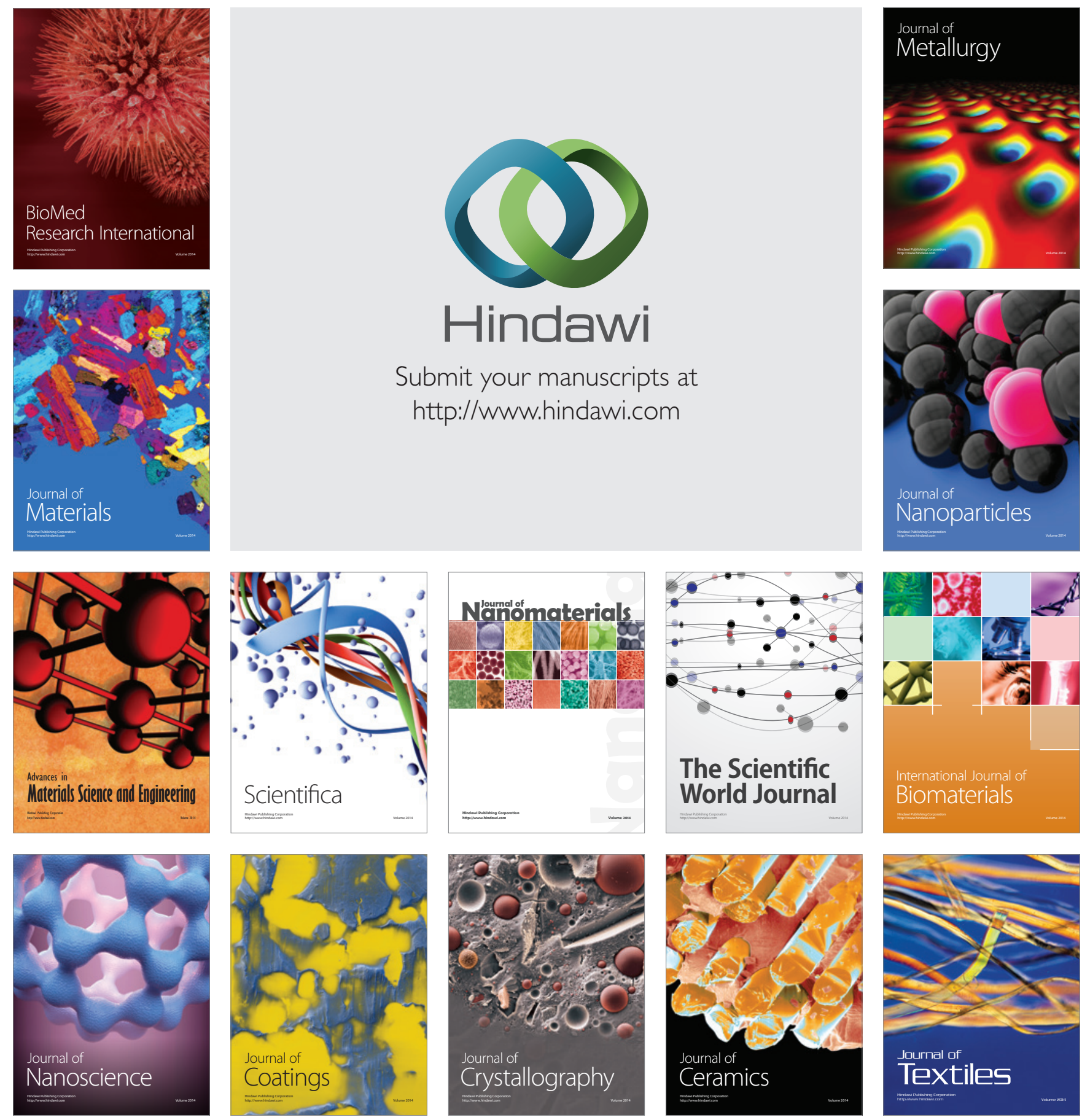